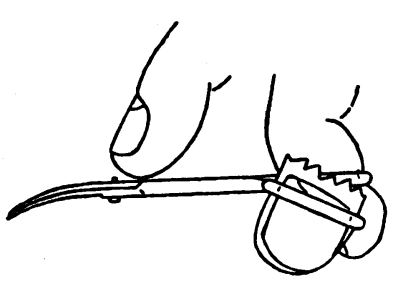

Fig. 1.-Cutting.

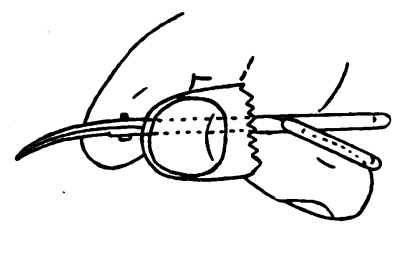

Fıg. 2.-Blunt dissecting.

The details are-length : $3 \frac{1}{4}$ inches; blades : curved on flat, with mean radius of curvature of 1 inch; points : fine, sharp, slightly ground off ; joint : screw; bow for thumb : angled at 20 degrees from the straight, as shown in Fig. 1. A transverse section of the joint or shanks (when closed) would be quadrilateral, the flat sides assisting the grip in blunt dissection, as shown in Fig. 2.

\title{
ANNOTATION \\ National Ophthalmic Treatment Board, Annual Report, 1936
}

This report classifies the working of the Board under three general headings (1) The conduct of investigations into matters affecting sight. (2) The education of the public to a realisation of the importance of medical eye examination in all cases of suspected defect of sight. (3) The administration of the National Eye Service.

Under the first heading investigations have been conducted on the care of sight in industry. A simple form of questionnaire had been drawn up during the summer of 1935 and was sent to a number of firms employing labour. As a result more than 400 firms from all parts of the country replied. These replies were classified and then subjected to statistical analysis, and the results were published as a special report in July, 1936.

For three successive years analyses have been made of the findings of a series of examinations of the eyes of patients who had obtained treatment through the medium of the National Eye Service. The findings of the three years are shown in tabular form. "The agreement in the findings of these three analyses is unquestionable and noteworthy, the more noteworthy, since each year the number of ophthalmic medical practitioners sending in 
returns has increased, so that each year's figures give what is virtually independent evidence."

" The broad fact elicited by these analyses of patients seen by ophthalmic medical practitioners is that out of 30,000 cases no fewer than 27.6 per cent. had ocular disturbances other than errors of refraction, and 7 per cent. had similar ocular disturbances without any errors of refraction ; altogether 34.6 per cent., or more than one-third of the patients had defects or diseases apart from errors of focus."

As a contrast to these figures the Board has been able to obtain those of certain of the approved societies, which are "in effect the findings or diagnoses of the sight-testing opticians."

It appears that only 3 per cent. of those of their members who took ophthalmic benefit through sight-testing opticians were referred for medical examination.

The Board's Annual Report insists on the fact that this discrepancy between the percentages of 34.6 and 3 per cent. is much too wide to be bridged. Attempts have, of course, been made to whittle away their significance, and the report discusses at some length a recent paper by an apologist for the sight-testing opticians which deals with these analyses. It says that " the positiveness of the apologist destroys his case. Where the trained ophthalmic surgeon walks warily, this optician skips with alacrity." As an instance his statements on glaucoma are quoted. "Glaucoma, 0.62 per cent. Rarely would the presence of this disease be overlooked by the ophthalmic optician. ... Although the disease is comparatively rare, the possibility of its presence and of its importance is so impressed upon the ophthalmic optician in his student days that he may be considered absolutely capable in detecting the condition and thus safe from the public point of view."

The second section of the report deals with education of the public, giving paragraphs referring to eyesight in industry, film propaganda, film projector service and Press articles. The last page of the report deals with the administration of the National Eye Service. This Service was established in 1929. The number of patients dealt with shows an increase of more than 32 per cent. as compared with the total number dealt with in 1935. The service now available in more than 400 places throughout the country has the assistance of nearly 900 specially appointed ophthalmic medical practitioners.

It is obvious that the Board is performing a public service to the community in more senses than one. We hope that the report will be studied by all concerned with the Public Health Acts. The attention of the Minister of Health should most certainly be drawn 
to it; for it appears by a recent communication from the Board that he "proposes to submit to Parliament during the current session provisional regulations, entitled "Additional Benefits Amendment Regulations, 1937," which will give power to an "Approved Committee" composed of Approved Society representatives and representatives of sight-testing opticians to compile a list of sight-testing opticians without medical training or experience as "Recognised" as qualified to examine the sight of the insured population and to detect pathological conditions should they be present."

The Chairman of the Board points out that there is no occasion whatever for this Register of sight-testing opticians. Before these amending regulations are passed we think that the Minister should not only give his reasons for this change, so that the profession may know exactly what they are, but he should be asked how his Department can reconcile a difference between 3 and 34.6 per cent. The last question should provide an interesting problem for the statisticians of the Ministry.

If a body of unqualified persons be publicly recognised, by registration, as competent to test sight and to detect pathological lesions when present, it will be a bad thing both for the insured and the country. We do not question the ability of most of the sight-testing opticians in the purely optical side of the subject. It is on the pathological side that they are likely to fail ; and if the idea that glaucoma is a comparatively rare disease is a fair sample of what they are taught, it makes us wonder how much value is to be placed on such teaching.

We call to mind a patient, a great sportsman, who came to us some years ago. He found that the glasses which he had procured from a branch of a well known firm of sight-testing opticians, made his eyes ache. The reason was obvious, the glasses were much too wide for his interpupillary distance. We asked him why he went to the shop in question. His reply was: "Oh, I saw - who used to play for Blackheath, going there one day and I thought what's good enough for him will do for me." Such a mentality is akin to that of Sydney Smith's hypothetical child who was told she might as well expect to please the Dean and Chapter of St. Paul's by stroking the dome; and reminds us of the elder Weller's sentiments about a good judge of cattle being a good judge of anything; an idea which, although Tony Weller didn't know it, is as old as the $\pi \rho \circ \beta a \tau 0 \gamma \nu \omega \mu \omega \nu$ of Aeschylus.

It would seem that the public need protection from such ideas and their possible consequences, which may not always be forthcoming if these amending regulations are passed. 